\title{
The causes of alimentary infertility of highly productive cows and prevention measures
}

\author{
Irina Mikhailova ${ }^{1}$, Tatiana Leshchenko ${ }^{2}$, Alexey Evlevsky ${ }^{1}$, Irina Ortyakova $^{1}$ \\ ${ }^{1}$ Don State Agrarian University, pos. Persianovsky, Russia \\ ${ }^{2}$ Kursk Federal Scientific Agrarian Center, Kursk, Russia
}

\begin{abstract}
In recent years, in connection with the importation of highly productive imported livestock into the territory of the Russian Federation, reproduction issues have become especially acute and have become an urgent problem of dairy cattle breeding. Their solution will ensure stable production of irreplaceable food products for the population of the country. According to many researchers, the most common cause of infertility in cows is metabolic disorders due to unbalanced feeding with a predominance of concentrated feed in the diet. As a result, in deeply pregnant and calving cows, pathobiochemical processes reach critical values, and a large number of animals are culled immediately after calving or in the first months of lactation. In the rest of the cows, reproductive disorders are observed and alimentary infertility develops. In order to correct metabolic processes and restore the reproduction function in cows, we proposed an energy-metabolic composition based on glycerol and succinic acid or sodium succinate. To determine its effectiveness, an experiment was carried out, as a result of which a high therapeutic efficacy of the drug was established, which was confirmed by the data of a biochemical study of the blood of experimental cows. Reproductive ability was restored in $85.6 \%$ of the cows of the experimental groups, which were fed with the proposed drug. In the control group, only $78.2 \%$ of the animals came in heat within 90 days after calving. Thus, the experiment has proven the effectiveness of the use of the energy-metabolic composition (glycerol with succinic acid or sodium succinate) for the correction of pathobiochemical processes and the preservation of the reproductive capacity of cows.
\end{abstract}

\section{Introduction}

For decades, the country's veterinary service has been paying great attention to the reproduction of the cattle population, which ensured the stable production of irreplaceable food products—meat and milk.

Many domestic scientists dealt with the problem of reproduction, for example, Professor V.S. Shipilov [1], while classifying the types of infertility, singled out alimentary, which occurs against the background of unbalanced feeding with low-quality feed. This problem has become especially acute in recent years, when imported highly productive livestock began to be brought into the territory of Russia [2].

For many farms, animal reproduction, retention of the placenta after calving, endometritis and other obstetric and gynecological pathology have become intractable issues [3]. In down-calving and freshcalving cows, pathobiochemical processes reach critical values, significant changes occur in the body of highly productive cows, therefore, they are culled immediately after calving or in the first month of lactation $[4,5,6]$. As a result, the terms of economic use of cows were reduced to two or three lactations. An indicator of the low level of reproduction of imported animals is the output of calves per 100 cows, which is about $70 \%$ at the country's dairy complexes. Such indicators cannot ensure both the reproduction and preservation of the genetic potential of highly productive cows, and the economic profitability of dairy complexes. The deplorable state of the complexes can be explained by the lack of the necessary knowledge and experience of work of domestic specialists with highly productive animals. Scientists warned about possible problems of keeping imported livestock; in their opinion, the use of energy-metabolic means could be a way out of this situation. However, in the current economic realities, many of the imported drugs and dietary supplements have become inaccessible to most households. For example, a single dose of any imported energy drink is more than 1000 rubles, which is ten times more expensive than edible sugar. There are practically no energy additives produced in Russia, therefore, a qualitatively different approach to the problem of ensuring the health of productive animals and the replacement of imported biologically active and energy additives with domestic preparations is required. It was this circumstance that 
was taken into account and served as the basis for the development of energy-metabolic tools from economically affordable, environmentally friendly and well-known components.

\section{Methods and Equipment}

The aim of the research was to develop and launch into production means of stimulating energy-metabolic processes in the body of highly productive cows to preserve their reproductive capacity.

For this purpose, we used our proposed energymetabolic composition based on glycerol and succinic acid or sodium succinate. (Fig. 1).

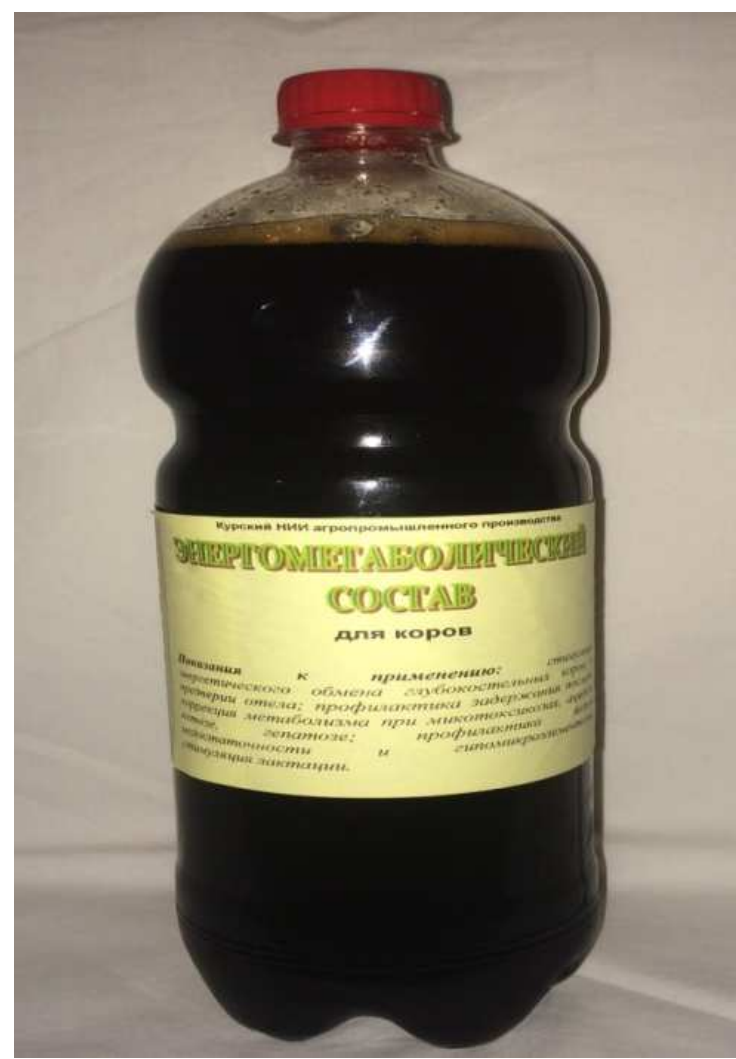

Figure 1: Energy-metabolic composition for cows

As comparison solutions, the following formulas were used: an aqueous solution of glycerin (150 g) diluted in drinking water in a volume of $500 \mathrm{ml}$ (composition No. 1); $150 \mathrm{~g}$ of glycerin with $15 \mathrm{~g}$ of succinic acid diluted in drinking water in a volume of $500 \mathrm{ml}$ (composition No. 2); $150 \mathrm{~g}$ of glycerin with 15 $\mathrm{g}$ of sodium succinate in a volume of $500 \mathrm{ml}$ of water (composition No. 3).

Model groups were formed from calving cows of the third lactation with a milk yield of $3800-4000 \mathrm{~kg}$ of milk according to the previous lactation, in which clinically expressed signs of ketosis and hepatopatosis were observed. Confirmation of the diagnosis in selected cows with clinical manifestation of the disease was carried out according to the results of biochemical blood tests. The main indicators for the selection of animals were reserve alkalinity, the level of ketone bodies and glucose. For an objective assessment of the effect of the compared energetics on the metabolism of the experimental cows, animals from each group were selected that had largely similar background biochemical parameters. (Fig. 2).

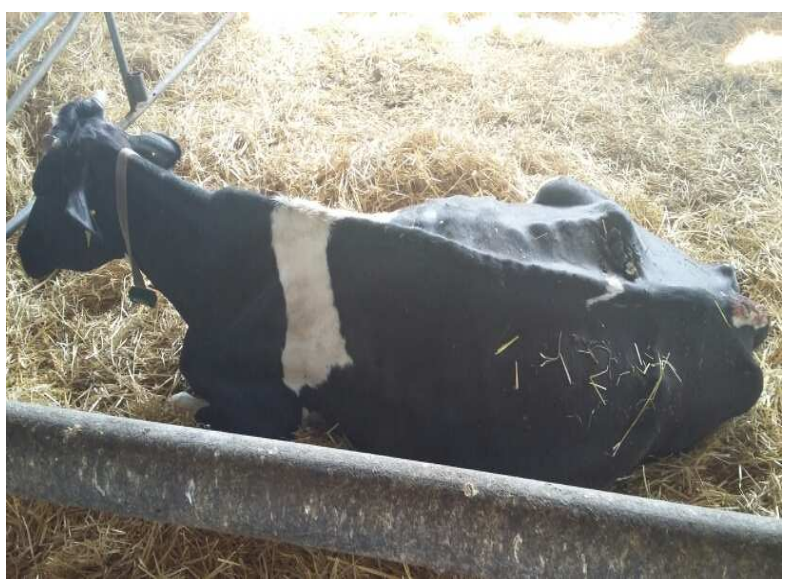

Figure 2: Clinical picture of ketosis

The experimental compositions were applied to cows as follows: in the first group, glycerin in monoform; in the second group, glycerin was drunk in a complex with succinic acid; in the third group, glycerin with sodium succinate, while the cows of the fourth group were control variant. The compared energy drinks were drunk from the first day of lactation once every 7 days for 30 days.

\section{Results and Discussion}

Currently, in animal husbandry, glycerin is used as an energy feed additive which is a trihydric alcohol. Unlike propylene glycol, it has a pleasant taste for cows, which greatly facilitates its use. Nevertheless, the first course of giving the drug was carried out by the forced drinking method. (Fig. 3).

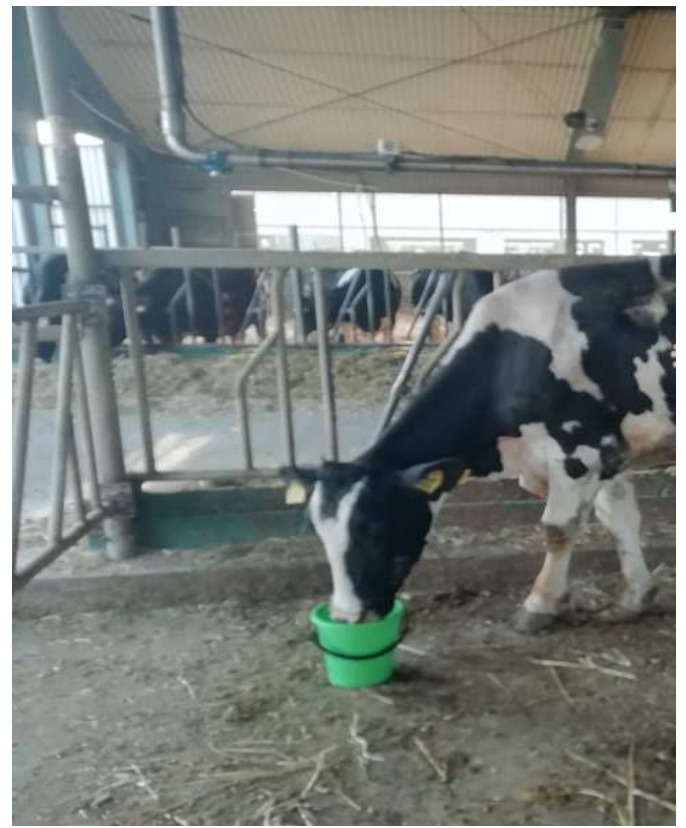

Figure 3: Individual drinking of the drug 
Glycerin is actively produced in the body of animals and is a natural metabolite. The inclusion of glycerin, like propylene glycol, in the diet is aimed at meeting the energy needs of the cows' body. However, the action of glycerin is short-term and in order to achieve the required clinical effect, a daily, long-term (up to 30 days) course of application is required. An increase in the energy activity of glycerin can be achieved by combining it with other biologically and energetically active components, in particular with propylene glycol. This approach is implemented in the RUMIPOWER series of energy feed additives for dairy cows. However, these supplements also have insufficient metabolic activity; in particular, they are ineffective in the development of clinical signs of hepatosis and severe intoxication.

To increase the metabolic activity of glycerol, we used succinic acid as a metabolism activator and hepatoprotector. Its positive effect on the body is found at relatively low doses $(0.5-1 \mathrm{mg} / \mathrm{kg}$ of body weight) [7]. It is also permissible to use the salts of succinic acid (sodium succinate), which in our experiments were obtained by neutralizing succinic acid with sodium bicarbonate.

Succinic acid and its salts (succinates) have a wide range of effects on various mechanisms of regulation of metabolic activity of cells. They are capable of increasing the detoxification activity of the liver tenfold, which is of significant importance in case of toxicosis and hepatosis. Another factor, succinic acid, provides additional energy to the cells of the gastric mucosa and improves digestion.

After analyzing the experimental data, we found that the combination of glycerol with succinic acid had a more pronounced effect on the correction of pathobiochemical processes. In biological studies of blood, on the 15th and 30th days, the average indicators of the reserve alkalinity in the cows of the second and third experimental groups were at the level of average physiological values. On the contrary, in cows that were fed with aqueous glycerol solution (first group), the value of this indicator increased. However, in the majority of animals it did not reach the lower limit of physiological values. At the same time, the indicators of cows in the control group decreased even more. An increase in the acid-base balance (reserve alkalinity) to physiological optimal values indicated a positive effect of the energy-metabolic composition on all biochemical processes in the body of cows. The improvement of carbohydrate metabolism was judged by a pronounced increase in the indicators of glucose content. In the group of cows fed with glycerin in monoform, a day later the level of this indicator was much higher than after two days. This can be clearly seen in the study of cows on the 15th and 30th days, which indicates the rapid involvement of the fed glycerin in energy metabolism and its short-term glucogenic effect. Therefore, to achieve a positive result, daily drinking is required, which is not economically viable.

Table 1: Biochemical parameters of blood

\begin{tabular}{|c|c|c|c|c|c|}
\hline & $\begin{array}{c}\text { Reserve alkalinity } \\
{[\mathrm{mmol} / \mathrm{L}]}\end{array}$ & $\begin{array}{c}\text { Total bilirubin } \\
{[\mu \mathrm{mol} / \mathrm{L}]}\end{array}$ & $\begin{array}{c}\text { KET } \\
{[\mathrm{mmol} / \mathrm{l}]}\end{array}$ & $\begin{array}{c}\text { Glucose } \\
{[\mathrm{mmol} / \mathrm{l}]}\end{array}$ & $\begin{array}{c}\text { Triglycerides } \\
{[\mathrm{mmol} / \mathrm{l}]}\end{array}$ \\
\hline \multicolumn{6}{|c|}{ Control group } \\
\hline $85.36 \pm 3.42$ & $15.62 \pm 0.85$ & $5.38 \pm 0.47$ & $1.9 \pm 0.03$ & $1.9 \pm 0.02$ & $0.45 \pm 0.03$ \\
\hline $87.54 \pm 3.49$ & $15.05 \pm 0.65$ & $6.19 \pm 0.46$ & $2.1 \pm 0.02$ & $1.8 \pm 0.03$ & $0.82 \pm 0.04$ \\
\hline $85.69 \pm 3.21$ & $15.04 \pm 0.69$ & $6.56 \pm 0.45$ & $2.7 \pm 0.04$ & $1.8 \pm 0.03$ & $1.06 \pm 0.05$ \\
\hline \multicolumn{6}{|c|}{ Experimental group No. 1 (glycerin in monoform) } \\
\hline $87.54 \pm 3.75$ & $15.76 \pm 0.84$ & $6.02 \pm 0.58$ & $1.9 \pm 0.03$ & $1.9 \pm 0.02$ & $0.57 \pm 0.03$ \\
\hline $88.34 \pm 3.52$ & $16.28 \pm 0.74$ & $5.42 \pm 0.43$ & $1.9 \pm 0.04$ & $2.3 \pm 0.04$ & $0.65 \pm 0.04$ \\
\hline $89.32 \pm 3.29$ & $16.56 \pm 0.78$ & $5.73 \pm 0.32$ & $1.8 \pm 0.03$ & $2.2 \pm 0.03$ & $0.87 \pm 0.05$ \\
\hline \multicolumn{6}{|c|}{ Experimental group No. 2 (glycerin + succinic acid) } \\
\hline $86.54 \pm 3.78$ & $15.22 \pm 0.45$ & $6.48 \pm 0.57$ & $1.9 \pm 0.03$ & $2.0 \pm 0.02$ & $0.56 \pm 0.03$ \\
\hline $85.64 \pm 3.23$ & $21.42 \pm 0.92$ & $5.86 \pm 0.48$ & $1.1 \pm 0.02$ & $2.8 \pm 0.04$ & $0.49 \pm 0.03$ \\
\hline $83.58 \pm 2.87$ & $22.36 \pm 1.04$ & $5.48 \pm 0.54$ & $1.1 \pm 0.02$ & $2.9 \pm 0.03$ & $0.44 \pm 0.02$ \\
\hline \multicolumn{6}{|c|}{ Experimental group No. 3 (glycerin + sodium succinate) } \\
\hline $86.49 \pm 3.56$ & $15.36 \pm 0.81$ & $6.53 \pm 0.38$ & $1.9 \pm 0.03$ & $2.0 \pm 0.02$ & $0.59 \pm 0.04$ \\
\hline $85.52 \pm 3.18$ & $23.45 \pm 1.05$ & $5.78 \pm 0.42$ & $1.0 \pm 0.02$ & $2.9 \pm 0.03$ & $0.46 \pm 0.02$ \\
\hline $82.46 \pm 2.75$ & $24.53 \pm 1.07$ & $5.32 \pm 0.34$ & $1.0 \pm 0.02$ & $2.8 \pm 0.02$ & $0.42 \pm 0.03$ \\
\hline \multicolumn{6}{|c|}{ Norm } \\
\hline $70-85$ & $19-27$ & $0.2-5.1$ & $0.3-1.2$ & $2.2-3.3$ & $0.17-0.5$ \\
\hline
\end{tabular}

Note: the top line is background indicators; middle row is indicators for 15 days; bottom line is indicators for 30 days.

In addition, under the conditions of intensive concentrate feeding and protein pressing, it was found that the use of energy-metabolic compositions made it possible to qualitatively improve the involvement of protein in energy metabolism, as evidenced by its lower parameters in the blood of cows that were fed the composition in combination with succinic acid or sodium succinate. A decrease in the level of ketone 
bodies in cows of these groups testified to the active involvement of lactate and keto acids in the energy metabolism when using the energy-metabolic composition, which had a favorable effect on the synthesis of glucose in the liver.

The biochemical parameters of the blood of cows that were fed with glycerin (first group) confirm our assumption that glycerol in monoform is only an energy source, which does not affect the maintenance of the metabolic function of the liver during periods of increased energy production. In this regard, to ensure the energy effect, its constant use is required, but at the high price of the drug, this is unprofitable. The combination of glycerin with succinic acid allows achieving a positive effect even with a relatively rare use (Table 1).
The achieved clinical results had a favorable effect on the indicators of the economic use of cows, increasing the safety of animals and restoring their reproductive ability, which is presented in Table 2 .

Thus, a technologically simple approach makes it possible to convert glycerol into an energy-metabolic composition with hepatoprotective activity, i.e. in the drug of therapeutic and prophylactic action. The development is protected by RF patent No. 2645769 [8]. The energy-metabolic composition, even in a diluted (ready-to-use) form, does not lose its qualities during long-term storage (exceeding 12 months), which is ensured by the preservative properties of glycerin.

Table 2: Influence of the tested preparations on the safety of lactating cows and the stimulation of their reproductive capacity

\begin{tabular}{|c|c|c|c|}
\hline Energy agents & $\begin{array}{c}\text { Number of } \\
\text { cows }\end{array}$ & $\begin{array}{c}\text { Dropped cows from the herd within 60 days } \\
\text { after calving } \\
\text { Number (\%) }\end{array}$ & $\begin{array}{c}\text { Came in heat within 60- } \\
\text { 90 days } \\
\text { Number (\%) }\end{array}$ \\
\hline $\begin{array}{c}\text { Glycerin + succinic } \\
\text { acid }\end{array}$ & 33 & $5(15.1 \%)$ & $24(85.6 \%)$ \\
\hline Glycerol & 32 & $9(28.1 \%)$ & $17(80.9 \%)$ \\
\hline Control & 35 & $12(34.3 \%)$ & $16(78.2)$ \\
\hline
\end{tabular}

When determining the therapeutic and costeffectiveness of the therapy, we found that the treatment regimen of animals in the first experimental group with the use of succinic acid allows for $54 \%$ faster to obtain a $100 \%$ therapeutic effect with a proportional acceleration of the restoration of the reproductive ability of cows.

\section{Conclusion}

Under production conditions, we have tested scientifically grounded, technologically simple, affordable and cost-effective approaches to the qualitative improvement of a fat-like energy agentglycerin-by obtaining an energy-metabolic composition. The development is protected by patent No. 2645769. In the course of clinical studies and scientific and industrial experiments, the effectiveness of the proposed composition was proved for the correction of pathobiochemical processes in metabolic acidosis, ketoacidosis and for the prevention of hepatopathology in lactating cows during the predicted periods of intensive involvement of their own body lipids in metabolism and their preservation reproductive ability.

\section{Acknowledgement}

This work was supported by the Don State Agrarian University.
The authors are grateful to their colleagues for their contribution and support to the study and all the reviewers who made a valuable contribution to the work on the manuscript and helped in its completion.

\section{References}

1. A. P. Studentsov, V. S. Shipilov, V. Ya. Nikitin, M. G. Mirolyubov, L. G. Subbotina, Veterinary obstetrics, gynecology and biotechnology of reproduction (Moscow: "Kolos") (1999).

2. V. A. Mishchenko, Veterinary Medicine of Kuban. 6. (2012).

3. V. Ya. Nikitin Russian veterinary journal. Spec. Issue, 4 - 5, (2007).

4. S. L. Boroznov, A. A. Matsinovich, Scholarly notes of UO VGAVM. 42(1), 142-144., (2006).

5. A. A. Evglevsky, I. I. Mikhailova, E. P. Evlevskaya, O. N. Mikhailova, T. I. Mikhaleva, T. R. Leshchenko, Journal "Veterinary pathology" 1 (55) 75-80, (2016).

6. S. N. Turnaev, Bulletin of the Kursk State Agricultural Academy, 9, 67 -69, (2014).

7. V. A. Mishchenko, Bulletin of Oryol SAU 2, 2024, (2008)

8. A. A. Evglevsky, RF Patent No. 2645769 Energy-metabolic composition for the prevention and treatment of ketosis and hepatosis in cows (02.28.2018). 